\title{
Geodesign Dynamics for Sustainable Urban Watershed Development
}

Timothy Nyerges ${ }^{\star \star}$ nyerges@uw.edu, Hrishikesh Ballal² hrishi@Geodesignhub.com, Carl

Steinitz ${ }^{3}$ csteiniz@gsd.harvard.edu, Tess Canfield ${ }^{4}$ tesscanfield@yahoo.com, Mary Roderick ${ }^{5}$

roderimj@uw.edu, John Ritzman6 jar29@uw.edu, Wilawan Thanatemaneerat ${ }^{7}$ wilawan@uw.edu

${ }^{1}$ Professor of Geography and Director of the Master of GIS for Sustainability Management

Program, Department of Geography, Box 353550, University of Washington, Seattle, WA 98195

${ }^{2}$ Centre for Advanced Spatial Analysis, Bartlett School, University College London

${ }^{3}$ A. and V. Wiley Professor of Landscape Architecture and Planning, Emeritus,

Harvard Graduate School of Design, and

Centre for Advanced Spatial Analysis, Bartlett School, University College London

${ }^{4}$ Landscape Architect, CMLI

${ }^{5} \mathrm{Ph} . \mathrm{C}$. in the Interdisciplinary Program in Urban Design and Planning, University of Washington,

Seattle, WA, 98195

${ }^{6}$ Master of GIS for Sustainability Management Program

Department of Geography, Box 353550, University of Washington, Seattle, WA 98195

${ }^{7}$ Department of Geography, Box 353550, University of Washington, Seattle, WA 98195, now

with, Royal Thai Government, Ministry of Natural Resources and Environment

"Corresponding author. 


\section{ABSTRACT}

Sustainable urban development is considered a complex problem. Geodesign applies systems thinking to such problems using a dynamic and collaborative process wherein iteration is necessary to address diverse objectives. Preparation and execution of a two-day research workshop explored two aspects of geodesign dynamics using a new software platform called GeodesignHub.com. One aspect of dynamics concerned the cross-systems influence of proposed projects and policies as related to ten systems (e.g. transportation, housing, surface water, forest preserves etc.) influencing watershed sustainability in King County, Washington. A second aspect investigated the interaction among six multi-disciplinary design teams and each pursuing different considerations in decision workflow processes. A decision workflow called the Steinitz Geodesign Framework was scoped, designed, and implemented to address meaningful and substantive policy and project proposals for achieving consensus on a 40-year plan design. Workshop participants addressed targets among ten subsystems for sustainable urban development. Findings suggest the software provided support for high-performance collaboration when teams moved toward their targets and when negotiating to achieve a single plan outcome, but the urban growth areas and or housing densities established through policy are likely in need of reconsideration to accommodate population growth. Conclusions about findings and prospects for future research are provided.

KEYWORDS: geodesign; sustainability; collaboration; systems thinking; sustainable urban development; watershed 


\section{Introduction}

Urban-regional decision problems are often called "wicked" problems because of their multidimensional character, including the diverse institutional-political perspectives involved in negotiating solutions that come in the form of agendas, stakeholder values and interests (Rittel and Webber 1973). To better characterize urban-regional decision problems, Nyerges and Jankowski (2010) developed a framework for differentiating, simple, difficult, complicated and complex problems, considering wicked a synonym for complex. A complex problem is one wherein any one or more of the content, structure, process, and context of subsystems within a larger system can change over time, due to the open system character of urban-regional landscapes. As such, meta-dimensions of content include institutional-political, social, economic, and ecological from which structural relationships emerge with process and context adding to the dynamic. Sustainable urban development (SUD) involves complex decision problems based on a sustainable systems perspective, wherein these meta-dimensions, and their more detailed sub-dimensions, interact (Nyerges et al. 2014).

Conventional planning approaches involve separate consideration of functional subsystems such as housing, transportation, or utilities. In contrast, SUD decision problems are challenging because a multi-system perspective is used, i.e. subsystems are considered functionally dependent. Watersheds are functional units composed of many subsystems; e.g., the systems mentioned earlier plus others such as industry, agriculture, surface and groundwater etc., that influence one another. Consequently, sustainable urban watershed development (SUWD) involves complex decision making as many subsystems are simultaneously involved. Two types of dynamics are often of interest for complex decision making involving SUWD. First, there are relationships between and/or among elements of systems that constitute system structure. Structure can change over time resulting in a structural dynamic. Based on structural change, subsystem processes can change over time as per natural and/or human agency. 
Thus, each subsystem might be considered an external context for situating other subsystems. Second, people commonly collaborate in decision workflow guided by 'stakeholder values' (Eikelboom and Janssen 2015), wherein sequence of treatment matters. Concurrency of treatment (called concurrency management in growth management) matters, as this motivation stems from system element interactions that try to avoid capacity shortfalls. For example, residential growth without adequate transportation infrastructure results in congestion, which is a complex problem in most metropolitan areas.

Whether through natural growth and/or migration, human population growth (including decline) together with consumption drives much of the dynamics within SUWD. Climate change and energy use are other drivers of change. This research uses population growth as a driver for SUWD, as human population growth particularly in coastal areas (NOAA News 2013), motivates concerns about growth management. Motivation for investigating decision dynamics of SUWD emerges from growth management laws involving concurrency management, wherein land use development must be accompanied with concurrent transportation improvements. Although housing, commercial, and industrial development have higher stakeholder values for most of the public, transportation and utilities can directly impact the former. As such, the capacity of roadways and utilities should be built before (or at least concurrently with) housing, commercial and industrial development. Consequently, in light of cross-system influences, SUWD decision processes play out as a sequencing of plan design proposal recommendations.

Current research about decision process workflow can be tracked to suggestions by Simon (1977) about a rational sequence of intelligence, design, choice, and reflection. Reviews of effective geospatial decision workflows have appeared over the decades including those that use GIS for group decision making (Jankowski and Nyerges 2001, Nyerges and Jankowski 2010). 'Design' as a second step in Simon's workflow is fundamental to decision creativity. 
Keeney's (1992) value-focused thinking in decision processes added insight for diversifying decision perspectives within groups, such that getting the right values as well as the values right for 'intelligence' is critical to addressing fundamental concerns that feed into design.

Steinitz at Harvard University developed and applied some early and fundamental ideas about macro-scale design in what is now called the Steinitz Geodesign Framework (Steinitz and Rogers 1970 , Steinitz 1990, 2012, 2013, 2014a). The result is a multisystem framework of models of landscape change that enable assessment and design of alternative futures. The framework addresses problems that are novel from both a design and from an analysis perspective, and has been put into practice for a number of years on large landscape change problems, often in the form of intense two- or three-day workshops using a mix of manual and computer support. The Steinitz (2012) Geodesign Framework is fully compatible with both Simon's and Kenney's frameworks, but offers further insight. Geodesign workflow is fundamentally different from conventional planning decision process. Geodesign is normally a multidisciplinary collaboration with direct interaction among design professionals, geographically-oriented scientists, and the people of the place, using available information technologies.

If complex problems like SUWD could be addressed by simple decision workflows then many problems about sustainable systems could be addressed by extant software. However, much of this software is designed with a single system focus, or hard-coded for a specific set of subsystem interactions (Sugumaran and Degroote 2010). Solutions will be more viable when complex decision workflows are made transparent extensible, and flexible with system-agnostic, simple-to-use software, the basis of the research challenge explored herein. Most software systems that are easy to use are often complex 'under the hood' because complexity is hidden by effective software capabilities presented through the human-computer interface. Since SUD 
complex problems involve multi-threaded decision workflows, it makes sense that information tools are now emerging that can provide support for open-ended and collaborative decision workflows. This article reports on geodesign research motivated by Steinitz, with software called GeodesignHub.com implemented by Ballal (2015), and used in a research workshop organized by Nyerges based on many years of experience with designing, developing and evaluating participatory tools (Jankowski and Nyerges 2001, Nyerges and Jankowski 2010). The following research question considers two dynamics for geodesign, a substantive dynamic about the interaction among system elements that influence each other in the world and a methodological dynamic about the way teams of decision analysts address the system interactions within a geodesign decision workflow.

Research Question: Given the dynamics of interaction within a complex urban system that occur among elements, how do decision analysts prioritize consideration of subsystem elements (values) and sequence their treatment using diagrams for synthesizing plan designs that address sustainable urban watershed development?

Findings about that research question are reported as follows. In section 2 we present the Steinitz Geodesign Framework by characterizing sustainable urban development problems, decision workflow, and workflow information tools which together motivated our study. Section 3 presents the research design of the study. In section 4 we report on findings as results from the three iterations of the geodesign decision workflow. Section 5 presents conclusions as insights about those results and prospects for research directions.

\section{Steintiz Geodesign Framework}

Addressing SUWD decision making involves many dimensions. Three of the main dimensions are the character of the problem, the nature of the workflow, and the information tools used to 
support complex decision workflow. Each dimension is treated in turn below to explicate the Steinitz geodesign framework for this research study.

\subsection{Decision Problems about Sustainable Urban Development}

Research about SUD has received significant attention over the past couple of decades to improve our understanding about transitioning to sustainability. Haughton and Hunter (1994) synthesized and outlined a multi-tier collection of principles for fostering sustainable cities. Kates and colleagues (Kates et al. 2001, Kates 2011) investigating sustainability science, with an emphasis on urban sustainability, use a derivative of Our Common Future report's definition of sustainable development to help focus the research (Brundtlund Commission 1987). Social, economic, and environmental conditions play a role in environmental assessment for SUD (Curwell, Deakin and Symes 2005, Deakin et al. 2007, Vreeker 2009) and for linking sustainability and resilience policy (Lizarralde et al. 2015). Simultaneous consideration of social, economic, and environmental conditions can help characterize housing, transportation, surface water and other systems when addressing the complexity of SUWD. While dynamics of system performance are important in assessment (Tsolakis and Anthopoulos 2015), decision problems also involve proposing solutions composed of collections (packages) of projects, e.g. like in improvement programming (Nyerges and Jankowski 2010). Sustainable solutions should consider diverse stakeholder perspectives to align with interests involved when addressing complex decisions (NRC 1996, 2002, 2005). We need to know impacts of proposed designs, in line with those stakes, before we make a decision about which collections of projects to pursue. Target goals, i.e., too much or too little of a level of system performance, are needed for sustainability management; whereas target goals are not needed for growth management, as we simply deal with (either too little or too much) growth of whatever is changing. SUWD is a system of systems problem. 


\subsection{Collaborative Decision Processes}

A solo designer/planner approach to SUD decision problems has been found lacking due to the need for discourse among multiple groups to engage in communicative rationality (Hopkins 2001); thereby supporting exploration of inter-relationships among functional systems in SUD (Tsolakis and Anthopoulos 2015). Several US National Research Council reports have explored the advantages of stakeholder-informed analytic-deliberative (AD) decision support processes wherein deliberation among stakeholders directs computer-supported analysis (National Research Council 1996, 2002, 2005). Jankowski and Nyerges (2001) developed enhanced adaptive structuration theory as a theoretical frame for AD workflow, applying it to large-group workflow (Nyerges and Aguirre 2011). Flexible structuring of decision workflow is at the core of decision situation assessment, wherein geodesign decision workflow is viewed as among the most comprehensive and flexible of approaches (Nyerges and Jankowski 2010). Key to $A D$ decision support is a participatory workflow that fosters 'information gain' through structured activities such as Delphi, Nominal Group, and Technology of Participation (Nyerges, Ramsey and Wilson 2006). However, none of those processes links assessment with intervention in the same way as geodesign can as an AD method.

The Steinitz geodesign framework combines analyses and deliberation to scaffold information gain while conveying insights about information uncertainties (Figure 1). The framework poses six questions that are treated in three iterations - forward flow, reverse flow and forward flow through six modeling steps (large arrows in Figure 1).

The six primary questions of the framework and their respective modeling steps are as follows.

1. How should the study area be described in content, space, and time? This question is answered by representation models, the data upon which the study relies. 
2. How does the study (system) area operate? What are the functional and structural relationships among its elements? This question is answered by process models, which provide information for the several assessment analyses of the study.

3. Is the current study area working well? This question is answered by evaluation models which are dependent upon cultural and scientific knowledge of the participants.

4. How might the study area be altered? By what policies and actions, where and when? This question is answered by change models, which will be developed and compared during the geodesign study. Change models generate data that will be used to represent future conditions.

5. What difference might the changes cause? This question is answered by impact models, which are assessments produced by the process models under changed conditions.

6. How should the study area be changed? This question is answered by decision models, which are dependent upon the cultural knowledge of the responsible decision makers.

Information gain is accomplished by using the output from one step as the input to the following step. This incremental approach to knowledge production also helps to consider information uncertainty within the workflow. Iterative cycles of modeling are possible until participants are satisfied; hence geodesign synthesis is often a non-linear process. There are many ways of developing synthesis through combining diagrams to make a design; diagrams being a general way to speak of information structuring that is recognizable by the audience intended, e.g. a portion of a map as a point, line, or polygon rendering the spatial footprint of a proposed policy or project. Some methods of synthesis are more effective than others, depending on the specific 
circumstances of the study (Steinitz 2014b). Sequence and speed of synthesis matters in decision workflow, as one of the foundations of high performance collaboration is rapid turntaking with rapid feedback. A design is a relational synthesis in space and time of system-based changes conveyed through diagrams. All changes are fed back to update the representation, process and evaluation models. Furthermore, each change has impacts across all systems. These are quantities and qualities and can be expressed as graphs, maps, and timelines. These interrelationships make geodesign a complex and dynamic process. Slow feedback for updates would drag out the decision workflow in a tedious manner. Rapid update offering rapid feedback is essential to move the workflow along. New AD geodesign software has been needed to address the above mentioned shortcomings.

\subsection{A Web Platform to Address Geodesign Dynamics}

Over the past few decades, geographic information system (GIS) technologies have matured, and are used throughout the world for sustainable development activities (Campagna 2005). Studies over the years have suggested the need for tools that help planners and designers be more effective (Bishop 1998, Voss et al. 2003). Several reviews exist that describe participatory geospatial information tools designed to combine analysis and deliberation (Balram and Dragacevic 2006, Brail 2008, Grossardt, Bailey and Brumm 2003, Jankowski and Nyerges 2001, Klosterman 1997, and Nyerges, Couclelis and McMaster 2011). Decision support software tends to be developed narrowly because of the complexity of space-time decision problems (Jankowski et al. 2006). Unfortunately, SUD decision problems are among the more complex problems, often having many dimensions. Consequently, extant software does not (yet) sufficiently fill a gap regarding rapid synthesis of scientific information together with creation of design proposals. Addressing that gap with tools that move sustainability science knowledge into decision support management practice is needed; particularly tools that support interpersonal engagement, planning discourse and collaboration (Brown and Kytta 2014). 
In 2014-15, the Steinitz geodesign framework was transformed by Hrishikesh Ballal into a server-based AD software tool called GeodesignStudy.com ${ }^{1}$ (Ballal 2015). The tool supports digital workflow through an open system wherein participants bring data and ideas into the tool, thus enabling participants to collaborate on plan design to address challenges of a region. The tool supports rapid synthesis of conceptual designs to address large and complex geodesign problems anywhere in the world having a reasonable Internet connection. The tool is fundamentally a design aid that interacts with commonly available GIS data and models and helps the users build a design. The tool specifies colors and graphic conventions as a shared language of communication and enabling broad collaboration among experts from diverse disciplines and non-experts. Tool design follows "Miller's Law: the magical number seven, plus or minus two" (Miller, 1956), and can accommodate any model if it can generate a map in up to five classes which are defined by specified colors. This enables multiple systems to be simultaneously addressed without cognitive overload. This purposeful simplicity respects Read's (1898, p. 351) advice, often attributed to John Maynard Keynes: "It is better to be vaguely right than exactly wrong." One of the more significant capabilities in the tool is an ability to address any of ten system themes using a dynamic update feature to visualize and document improvements to any and all ten systems evaluation maps that depict performance of systems. This capability was introduced into the GeodesignStudy.com software in preparation for the University of Washington (UW) Workshop for testing and evaluation, and in many respects motivated Nyerges to convene a geodesign dynamics research workshop. In practice, the software is most useful when applied at the beginning of a study of considerable complexity, comprising multiple objectives and perspectives, several unknowns, and in need of an overarching strategy.

\footnotetext{
${ }^{1}$ The current version of the software and its extensive self-help documentation are publically
} available and free to use at GeodesignHub.com. 
Collaboration supported by the tool is organized using four types of interaction roles in the form of a hierarchy of responsibilities (Figure 2). System administrators manage projects; each project similar to the UW workshop constituted of a topic and a collection of participants. The administrator supports those who conduct a workshop (conductors), e.g. in the UW case, this was Steinitz and Nyerges. Coordinators are those who collate contributions from participants in a geodesign team. Any and all participants are free to offer design ideas as projects and policies during execution of a workflow agenda organized by conductors as part of a study design.

\section{Study Design about Geodesign Dynamics}

Addressing geodesign scoping, design and implementation iterations depends on the amount of time participants will dedicate to collaboration; many professionals know that collaboration can be expensive. Since a research-oriented two-day workshop was envisaged, workshop organizers Steinitz and Nyerges decided that a considerable amount of work would be performed 'up-front' before convening a face-to-face meeting. Workshop convener Nyerges suggested SUWD as a topic, and reached out to an advisory committee about an appropriate study area, and enumerated a list of participants with help from the advisory committee.

Once those aspects of the workshop were identified, then the study team worked together to establish the two-day workshop agenda, although Steinitz and Nyerges took the lead given their respective backgrounds with workshop facilitation. The research workshop was meant to emulate a diverse multi-stakeholder activity for exploring geodesign dynamics in both subsystems interaction as well as decision making workflow. Since geodesign applies systems thinking to the assessment of circumstances and creation of policies and proposals for change and simulation of impacts, as well as the prioritization/negotiation of results, it is necessarily a dynamic process. Thus, organizers/conductors configured a two-day agenda and invited 24 
participants. Participants were to be organized into six small-group geodesign teams of 3-4 each, depending on who actually arrived to participate. With growth management in mind, the study team selected a sustainability plan for $a+20$-year and +40 -year time horizons as the main goal, while taking into consideration ten subsystems of a watershed study area.

\section{Results from Geodesign Decision Workflow as Three Iterations}

As mentioned earlier, a geodesign study addresses six primary questions and their subsidiary questions at least three times (Figure 1). In the first iteration, the questions are asked rapidly, beginning with question 1 proceeding to question 6 . They define the contextual scope of study, asked as $\mathbf{W H Y}$ questions for a study. In a second iteration, the six primary questions are asked in reverse order from 6 to 1 as the HOW questions to specify study methods; they design the computer techniques to be used. In the third iteration, the six questions are asked again in order 1 through 6 to implement the synthesis stage of workflow, addressing WHAT, WHERE, and WHEN questions. Iterating through the six questions/models enables 'honing in' on alternative proposals that lead to a recommended plan. Whether addressed explicitly or implicitly, all six questions must be satisfied throughout all three iterations of the framework to complete a geodesign study. Below we report on findings from the three iterations of the study.

\subsection{Findings from Iteration 1: Preparation for the Workshop that Answers WHY}

In this first iteration, the six questions were asked in order from 1 to 6 to answer $\mathbf{W H} \boldsymbol{Y}$ the study was about watershed sustainability within a +40 -year timeframe, given that communities in Washington State (WA) plan under growth management regulations. Metropolitan Seattle (four counties within central Puget Sound) is among the ten fastest growing areas in the US in terms of employment and population according to Forbes Magazine (Forbes Magazine 2015). King County is the most populated county in the region, with just over 2 million residents in 2013. From 2000 to 2012 the county grew by 11 percent. Given its diverse economic base, the area 
is expected to continue this trend of growth into the future. This population growth would be the basis for addressing sustainability. Watersheds are functional areas not often considered as a basis for growth management planning areas; thus, we experimented with a systems thinking perspective to underpin a sustainability management perspective. The WA Growth Management Act (GMA) of 1991 directs counties and cities to plan in accordance with growth management elements, herein each considered to be a system. Table 1 presents a comparison among WA GMA elements, the chapters of the King County (2015) Comprehensive plan, and ten systems of concern within watersheds. The ten systems combined were assumed to represent a complex system. In Table 1 the numeric system labels reflect vulnerable to change systems (1-5) and attractive for change systems (6-10) listed in order of sensitivity to change.

\section{Table 1. Ten Systems Considered in the Geodesign Study}

King County plans at four scales: region-wide; county-wide; small area; and sub-area. Two subwatersheds within Green-Duwamish River watershed, or what Washington State agencies call Water Resource Inventory Area 9 (WRIA9), were selected as the study area to allow participants to investigate watershed sustainability as a complex systems problem (Figure 3). The Lower Green River subwatershed lies inside the King County designated urban growth area boundary while the Middle Green subwatershed is largely outside the urban growth boundary. Both contain a mixture of urban, suburban, and rural land uses. The small area included three medium-sized cities from a WA State perspective (Renton, Kent and Auburn), so the 'small' is relative to county extent. Like much of western WA, the area is subject to salmon endangered species recovery that influences local growth management; salmon are in backyard streams.

The study was scoped to address change for +20 - and +40 -year plan time horizons. Population predictions estimate that 200,000 new people are likely be added to the combination of subwatershed areas by 2035 , and that number will grow by an additional 220,000 people by 
2055. These estimates are linear extrapolations of the trends in population growth, and although suspect to error, provided the basis for acreage projections to be protected or developed using the +20 -year (2035) and +40-year (2055) targets in the right column of Table 2 . The target goals (acreage) are developed in line with a sustainability management perspective, i.e., growth management does not normally identify goals to answer how much is too little and how much is too much of something (Nyerges and Jankowski 2010), but sustainability management would.

Table 2. Twenty and Forty-year Targets for Ten Subsystems Motivated by Population Growth

This complex planning problem provided the opportunity to explore the usefulness of the geodesign method within the context of sustainability management for complex urban systems. Articulating a 'system of systems' is not straightforward, but using a collection of systems themes that interact and are likely important to many people can be appropriate. Differentiating between closed and open systems, a closed system is one that has no exogenous influence, and thus no context of change. The study area is an open system, and all its subsystems are open systems, as their spatial and temporal context as defined by inter-relationships with other systems matter (Nyerges et al. 2014).

We found that the WA State growth management elements and the King County Comprehensive Plan nine chapters to be a sound way to specify ten subsystems for geodesign; an approach the could be repeated in all counties of Washington State, as well as anywhere multi-functional comprehensive plans exist for local communities. Ten is a convenient number as it is not too small and not too large for enumerating subsystems within a complex system as enabled by GeodesignHub.com software. When subsystems are grouped into two categories, one category for 'vulnerable to change' systems and one category for 'attractive for change' systems, the study team thought they simplified the design problem, but waited for the next 
iteration to clarify developed/protected change. The number of target acres to be developed/protected for respective subsystems were based on population projections. The projection was a simple linear increase across years, which is simpler than what will likely occur. Nonetheless, the study team found the targets for total acres to be developed and protected were easy to understand as a basis for grounding realistic complex decisions.

\subsection{Findings from Iteration 2: Preparation for the Workshop Answering HOW}

Iteration 2 was used for organizing a sequence of models to answer the HOW questions; working from question 6 to question 1. The answers are model-driven rather than data-driven; a major difference using GIS for decision support as opposed to using GIS for problem exploration. The study team recognized that all workshop participants should take part in the iteration, especially in defining the data needs. Although time limitations prohibited participation by more than the study team members (authors), the seven team members found sufficient but not overwhelming diversity in their deliberations to design the methods as follows.

Decision models vary by interest group, and thus stakeholder values. The decision model for each design team is established using the ten systems of study. The team must agree on the relative importance (value) of these ten systems.

Impacts among the ten systems were classified into two categories, 'systems vulnerable to change' and 'systems attractive to change'. The first category highlights the importance of 'protection' as the system resources they represent are often fragile and in short supply. The second category is one that represents immediate needs of increased populations, or a need which must expand if population growth is to be accommodated in that area. A five-level impact model was designed for each system, summarizing potential positive or negative impacts of projects generated from all systems upon that system's several levels of evaluation. Five-level 
maps (most positive to most negative) were to be used in the workshop; however, the template did not require that all five levels be used. Inter-connections among systems were represented in a cross-systems impact matrix for how the potential positive or negative impacts add together to change a system's attractiveness or vulnerability as a result of the actions of all other systems (Figure 4). The matrix was specified by the study team; however, we recognized that the matrix should have been reviewed by all collaborating experts of systems. The cross-system dynamics summarized in this template dynamically modify and update the evaluation models as designs are developed.

The most important consideration in selecting a design method involves certainty of the geodesign team about the decision model and the assumptions of the problem (Steinitz 2014b). Anticipatory, participatory and sequential design methods all assume (relative) certainty about system relationships, i.e., relationships as part of a closed system. In contrast, combinatorial and constraining approaches assume uncertainty and therefore explore assumptions and requirements before integration and commitment into a design, i.e., considerations as part of open systems relationships. Rule-based, optimized, and agent-based design methods presume certainty about model scope, but assume uncertainty in parameter assumptions and in the final design outcome, i.e., partly closed and partly open systems relationships. The constraining method was selected for the purposes of the workshop because ten systems, all with considerable uncertainty as part of open complex systems, were the focus of the design effort.

Evaluation models are derived from decision models, and are based on the stakeholder-driven assessment of impacts of proposed design changes when compared to the present or projected states. Evaluation models directly influence change models by guiding a design to areas which are in need of a change while highlighting areas which should be protected based on criteria. Evaluative criteria can be conveniently grouped into three categories: site, situation, and 
administration. Site derived criteria relate to the physical characteristics of specific place, such as terrain, geology and ecology, and demographics. Situation derived criteria extend into the surrounding 'neighborhood' areas and include larger spatial effects such as roadway accessibility or upstream hydrology. Administrative criteria include public property, zoning and planning laws and regulations. The growth management regulations within King County were used as the basis of our evaluation maps. An evaluation template consisting of a five-level ordinal ranking scheme was applied to all ten systems. Each of the ten systems was to be described in terms of its attractiveness or vulnerability, based on agreed criteria. The study area was described in five levels ranging from most to least using a scale of dark green, light green, yellow, red and dark red. When overlaying any combination of ten systems, dark green indicates requiring change while dark red indicates protection.

Process models are linked with impact models, which are purposely formulated in a generalized and aggregated manner. A geodesign team must consider complexity of process and impact models to adequately inform the study. If a generalized model is insufficient for any selected system, an external and more complex model is necessary. The geodesign team simplified the process models by adopting the impacts update model as the basis of influences.

The aim for creating a representation model was to acquire, organize, and use a minimum amount of data for each of ten systems. The outcome of iteration 2 is a representation model in the form of a database design that includes criteria describing five levels of system performance for each of the ten systems. As adopted from the evaluation model, green means 'go' whether for protection or for development in the respective systems. A major challenge involved how criteria for vulnerable systems were inversely related to those of protection, but must be arrayed so that red categories share a sense of 'avoid change' and green categories 'go for change'. 


\subsection{Findings from Iteration 3: Answering WHAT, WHERE, and WHEN}

Iteration 3 implements the results of iteration 2 by asking WHAT, WHERE, and WHEN concerns about questions 1 to 6 . Implementation of models 1 - 3 was a pre-workshop activity; whereas, implementation of models 4 - 6 was part of the face-to-face workshop session.

The result of the representation model implementation was a 2015 land use map that included all ten systems using data obtained from King County GIS Data Center. Geodesignhub.com allows any map to be seen at several scales, on several base map formats. However, as with all GIS maps, the data must be registered to a common coordinate system for portrayal.

The study team implemented process models by acquiring data generated from these models. Thus, system dynamic was not processed by the study team, but acquired. As such, the spatialtemporal modeling aspect of the study is an important aspect of future research.

Study team members evaluated past and present conditions on a system-by-system basis using information acquired from process models. The evaluation used a five-level scale (dark green to dark red) described earlier. Study team members most knowledgeable about each system stepped forward to evaluate it; while all other study members helped critique the evaluation. Multiple iterations were used to refine the evaluation maps, comparing them against each other.

The workshop was convened on May 6-7, 2015. All sessions were video recorded, and are available online through YouTube (UW Geodesign Workshop 2015). Before organizing design teams, participants were asked, based on their own expertise, to propose design changes as projects and/or policies that would protect vulnerable areas and/or improve areas attractive for development. These were depicted as color coded diagrams, rank-ordered and numbered by 
potential efficacy, and placed in the diagrams grid of the GeodesignHub.com software. These projects and policies 'seeded' the design proposal database for all teams.

Workshop conductors organized six change-synthesis design teams, each with three or four persons, to consider change model proposals at 20- and 40-year horizons. Since the evaluation maps were created in the context of existing growth management policies, the workshop conductors combined two stakeholder-views (pro-development or pro-conservation) with three growth-policy scenarios (relaxed statutes/policies, maintained statutes/policies, or enhanced statutes/policies) to form six design teams (upper part of Figure 5). Workshop participants were assigned to teams on the basis of mixing their interests and expertise. The initial task for each team was to consider the problem overview and develop the team's decision model based on their priority given to each system (lower part Figure 5). Color bars (ordered left to right in Figure 5) prioritize the ten systems for each of the teams. The six teams worked separately, but shared all aspects of the exercise, including diagrams and design decisions.

Participants proposed additional policy and project diagrams as per their stakeholder interests in the study area. They drew change diagrams as points, lines or area polygons. Diagrams were added by participants at any time to the design database, and were shared when working in collaboration mode. Participants proposed and/or simulated future changes by selecting and combining diagrams as needed into their designs. Policies were developed as cross-hatched areas; however, only projects were assessed for their direct impacts.

Participants used the GeodesignHub software to assess and compare the impacts of each change design model. Impacts are computed relative to the target goals for developed or protected acreage for each of the five developable and five vulnerable systems, respectively. Several types of maps, histograms, and diagram displays could be created to help participants 
interpret impacts after real-time updates. Impact displays are used to gauge how designs perform in light of the target goals, but the pro-development and pro-conservation perspectives encouraged focus on targets aligned with these perspectives. Pro-development and proconservation teams were not provided any details to direct their stakeholder priorities; as they were free to develop insights through group-directed discussions. Unfortunately, the study team did not record details about priorities, except of course for the maps used to represent those priorities positions. In general, we found that participants visualized and discussed how infrastructure (utility and transportation) systems influenced development conditions (constraints) for other systems, e.g., dramatically affecting the high density housing and commercial and industrial development. This issue emerged because teams wanted to develop housing outside of the urban growth boundary (Middle Green subwatershed) and/or protect more green space inside the urban growth boundary (Lower Green subwatershed). This tension in development and protection arose frequently in those discussions. The issue is interesting from a concurrency perspective, because concurrency between land use development and transportation is a central issue in growth management planning.

A decision model was used by participants to assess and compare the impacts of design versions, making one of three decisions based on their group priorities: "No," which required feedback, or "Maybe," which encouraged further study at a different size or scale, or "Yes," which led to concluding steps for about decision synthesis and possible implementation. Several ways of comparison led to a final "Yes" decision for teams. First, the spatial arrangements of the designs as reflected in the six decision models were compared. Using comparative graphics, general priorities for pro-development teams $(1,2$, and 3$)$ were interpreted from the results of the team actions. Teams 1 and 3 set a high priority for utilities development. Teams 1, 2, and 3 set a high priority for transportation development, set a medium priority for commercial/industrial development, and set a lower priority for vulnerable 
systems: surface water quality, agriculture, and groundwater. Two information types (maps and grids) working together were used for comparing designs, both providing a different way of viewing information content, i.e., a synoptic view using maps and a detailed inspection of projects by systems using project diagram grids.

Overall, a +40 -year plan design was developed by combining all diagrams used by at least 3 of 6 teams. The combined diagrams showed the character of agreement possible over the watershed and across the teams, particularly in regards to higher density mixed use corridor development. An assessment of uncertainty was made using a rule-of-thumb -- muddied colors show disagreement among areas. Continuing to explore agreement and disagreement, conductor Steinitz directed teams in development of a sociogram on a grease board; a sociogram assesses team likelihood to collaborate on the basis of similarity of designs. From this, two affinity groups emerged: teams 2 and 6; and teams 1, 3, 4, and 5. Single family housing is one system that is clearly evident in the design from teams 2 and 6 , with it expanding from the +20 -year to the +40 -year time horizon. Preservation of the critical area is also evident in the +20 -year, but does not expand much in the +40 -year plan. Combining plans from teams 1, 3, 4 and 5, the expanded transportation and sewer infrastructure in the +20 -year plan is utilized by higher density development in the +40 -year plan. The agriculture area stays the same. Riparian corridors are included in the +20 -year, but do not expand much in the +40 -year plan. The two affinity groups then negotiated, first by agreement, and then by editing and/or trading policies and projects in the diagrams. Each made +20 and +40 designs within about an hour, which in any decision workflow would be considered high performance collaboration.

Because of noticeable similarities in the two designs, one final design was negotiated within about an hour (Figure 6). Intensive development in the final agreed +40 -year design occurs mostly in corridors across the watershed. However, a backdrop of low-density infill housing (in 
yellow) is also seen. The large polygon to the east is a forest protection area which is the portion of the watershed that feeds the Green River. Overlapping polygons where the colors in the land use legend are "muddied" show uncertainty about the extent of the proposed activities. The cross-hatched areas are the policies applied, rather than projects undertaken. Among the most interesting findings is that two teams were to follow the current market and growth policies and two which were to relax them. However, none did. Three (and also the two teams that were to enhance policies) converted to higher density and public transport before +20 years in order to keep the growth boundary where it is. Most importantly, the one team that tried to follow the free-market for low density residential, based on conductor encouragement, had to 'break free' of the growth boundary at +20 years.

The final +40-year design was used to update the evaluation models to projected 2055 conditions. We found that developments in some systems could enhance potential for development for other systems. The land use and transportation concurrency comparison makes sense, but when drilling down to what kind of land use, we found how the spatial coverage of utilities improvement affected high density housing. When participants exercised the dynamic updates they commented on the ease and effectiveness of the displays to foster plan (project package) creation. It appears that rapid updates (turn-taking) fostered high performance collaboration with plan design creation.

\section{Conclusions and Prospects}

The research question about geodesign dynamics contained two emphases, one about interaction dynamics of systems and the other about interaction dynamics of workflow. Conclusions and prospects for each are provided below. 
Ten subsystems within a comprehensive plan for growth management still make sense; but of course articulation of which ten systems matters. For that reason, we chose a systems perspective that aligns with state-mandated elements of the county growth management planning process. The workshop demonstrated how we might deal with multiple interactions among relevant systems now and in the future. In the final plan, utilities and transportation have significant roles in guiding development, while conservation of riparian corridors addresses vulnerability of systems in the watershed area. Because of undulating topography, transportation and riparian features frequently share a corridor, where high-density housing will likely emerge to take advantage of transportation and scenic beauty. A tension between development and protection arises frequently in sustainable development discussions, but it is not a new issue. However, this research sheds new insight on the issue from a concurrency management perspective. Knowing that concurrency management is a central issue in growth management planning, we conclude that concurrent change among all systems could be the underpinning to sustainability management more broadly. That finding leads us to hypothesize that sustainable development might 'turn' on the basis of some of the inter-system comparisons, as land use systems influence transportation systems and these in turn influence stormwater systems that influence ecosystems, etc., in which feedback links abound. Being able to perform cross-system assessment that leads to cross-system intervention is a key to sustainable systems design for capital improvement programs. Despite these insights about interaction between and among elements, we still do not know how well the complex system is performing per se. A collection of system indicators might have provided insight about system performance, but this suggestion must wait until a future workshop and more robust models to provide the cross-impact information.

Exploration of dynamics in the geodesign decision workflow was a second emphasis. Lack of full participation in pre-workshop scoping and design was clearly a lesson learned about the link 
between substantive and methodological domains. Several participants during the workshop commented about a need for more information about each of the subsystems. That comment reflects back on the absence of participants in pre-workshop model and data development. Central to the workflow dynamic was the capability for rapid turn-taking, providing immediate feedback. Although we knew it would be helpful, the workshop showed just how helpful. In previous workshops, it might have been possible to have three or four versions of a design. One team had seventeen, which clearly showed that immediate feedback of a synthesis of plans is extremely helpful in consensus building. Given that spatial-temporal process models were not developed, we still have yet to fully understand the character of the ten systems problem in regards to dynamic system performance in a decision setting.

Prospects for SUWD 'on the ground' are conditioned by a collective understanding of future and changing population densities. Everyone considered how changing to a higher density housing strategy would be beneficial. A recently published proposal by a Seattle Mayor's task force on housing affordability suggested that: Seattle can NO LONGER ACCOMMODATE SINGLE FAMILY ZONING (Seattle Times 2015). However, the Mayor's Office is not at this time ready to sponsor that recommendation. Such a proposal suggests that higher densities are needed for the region. Although our study area in King County is outside the City of Seattle, feelings favoring single-family homes abound in the marketplace. There is no doubt that low densities within areas adjacent to growth boundaries establish a sustainable urban development tension; but the more important issue for sustainability concerns 'how long can it persist'. Prospects for higher densities based on infrastructure investment and public transport are needed. The clear lesson is that we cannot have both low density and the growth boundary after +20 years into the future.in this area; thus, infrastructure planning and zoning change is needed now. 
GeodesignHub.com is cyberinfrastructure-enabled GIS (CyberGIS) software that emphasizes high performance collaboration rather than high performance computing, but both are needed (Roderick, Nyerges and Avraam 2015, Wang et al. 2013). Although prospects for facilitating geodesign dynamics through CyberGIS software look promising, the complexity of SUD decision problems still outpace computing capabilities developed to date. Consequently, CyberGIS platforms that foster analytic-deliberative decision support with both interpretations of HPC are needed, particularly to support very large participatory efforts in asynchronous remote interaction (Nyerges, Roderick, and Avraam 2013). Such platforms move beyond the planning support systems and decision support systems now available. Such integration could be a next step in 'supercomputing for society', i.e., making supercomputers useful for complex problems of the everyday world. It will take a broad-based open system, transdisciplinary community effort to realize this potential. 


\section{ACKNOWLEDGEMENTS}

Partial support for convening the workshop was provided by National Science Foundation CyberGIS Project grant no. OCl-104791, Advanced Cyberinfrastructure Division, Software Integration for Sustainable Innovation Program as part of Cross-Directorate Active Programs, Geography and Spatial Sciences, and Method, Measure \& Statistics Programs. Additional support was provided by the University of Washington's Department of Geography, the Master of GIS for Sustainability Management Program, UW Participatory GIS Technologies Group, College of Arts and Sciences, Department of Civil and Environmental Engineering, Department of Urban Design and Planning, and Department of Landscape Architecture. The findings are those of the authors and do not necessarily reflect the views of the organizations providing support. The authors would like to thank the workshop participants for their time and energies associated with exploring geodesign dynamics. 


\section{References}

Ballal, H. (2015) Collaborative planning with digital design synthesis, Doctoral dissertation, University College London.

Balram, S. and S. Dragicevic (eds.) (2006) Collaborative Geographic Information Systems, Idea Publishing, Hershey PA.

Bishop, I. D. (1998) Planning support: hardware and software in search of a system. Computers, Environment and Urban Systems, 22(3):189-202.

Brail, R. K. (2008) Planning Support Systems for Cities and Regions. Lincoln Inst of Land Policy, Cambridge, MA.

Brown, G. and Kyttä, M. (2014) Key issues and research priorities for public participation GIS (PPGIS): A synthesis based on empirical research. Applied Geography, 46:122-136.

Brundtland Commission (1987) Our Common Future. Oxford University Press, Oxford, England.

Campagna, M. (ed.) (2005) GIS for Sustainable Development, CRC Press, Boca Raton, FL.

Curwell, S. M. Deakin, M. Symes (2005) Sustainable Urban Development, Vol. 1, The Framework and Protocols for Environmental Assessment, Routledge, London.

Deakin, M, G. Mitchell, P. Nijkamp, R. Vreeker, (2007) Sustainable Urban Development, Vol. 2, The Environmental Assessment Methods, Routledge, London. 
Eikelboom, T. and Janssen, R. (2015) Comparison of geodesign tools to communicate stakeholder values. Group Decision and Negotiation, pp.1-23.

Forbes Magazine (2015). America’s Fastest Growing Cities 2015.

http://www.forbes.com/pictures/emeg45eegeg/5-seattle-wash/

Grossardt, T., K. Bailey, and Brumm (2003) Structured Public Involvement: Problems and Prospects for Improvement, Transportation Research Record, 1858, pp. 59-102.

Haughton, G. and Hunter, C. 1994 Sustainable Cities, London: Jessica Kingsley Publishers.

Hopkins, L. D., 2001. Urban Development: The logic of making plans. Washington, D.C., Island Press.

Jankowski, P. and Nyerges, T. (2001) Geographic Information Systems for Group Decision Making, Taylor \& Francis Publishers, London.

Jankowski, P., S. Robischon, D. Tuthill, T. Nyerges, and K. Ramsey (2006) Design Considerations and Evaluation of a Collaborative, Spatio-Temporal Decision Support System, Transactions in GIS, 10(3): 335-354.

Kates, R.W., et al. with 20 others, (2001) Sustainability science. Science, 292, 641-642 Available from: http://www.hks.harvard.edu/var/ezp_site/storage/fckeditor/file/pdfs/centersprograms/centers/mrcbg/programs/ssp/docs/documents/2001/Kates_Science_2001.pdf [Accessed online 10 March 2016]. 
Kates, R.W. (2011) From the unity of nature to sustainability science: ideas and practice. CID Working Paper 218. Cambridge, MA: Center for International Development, Harvard University. Available from: http://rwkates.org/pdfs/a2011.02.pdf [Accessed online 10 March 2016].

Kenney, R. (1992) Value-Focused Thinking: A Path to Creative Decision making. Harvard Press, Cambridge.

King County (2015). King County Comprehensive Plan, 2013 Update. Accessed February 1, 2015. http://www.kingcounty.gov/depts/permitting-environmentalreview/codes/growth/CompPlan/2012Adopted.aspx

Klosterman, R. E. (1997) Planning support systems: a new perspective on computer-aided planning. Journal of Planning education and research, 17(1):45-54

Lizarralde, G., K. Chmutina, L. Bosher, A. Dainty (2015) Sustainability and resilience in the built environment: The challenges of establishing a turquoise agenda in the UK, Sustainable Cities and Society, 15 (2015) 96-104.

Miller, G. (1956) The Magical Number Seven, Plus or Minus Two: Some Limits on Our Capacity for Processing Information, The Psychological Review, 1956, 63:81-97.

NOAA - National Oceanic and Atmospheric Administration (2013) NOAA News, NOAA, U.S. Census report finds increases in coastal population growth by 2020 likely, putting more people at risk of extreme weather, http://www.noaanews.noaa.gov/stories2013/20130325_coastalpopulation.html 
National Research Council (1996) Understanding risk: Informing decisions in a democratic society. Washington, DC: National Academy Press.

National Research Council (2002) Community and quality of life. Washington, DC: National Academy Press.

National Research Council (2005) Decision making for the environment: Social and behavioral science research priorities. Washington, DC: National Academy Press.

Nyerges, T. and Aguirre, R. (2011) Public Participation in Analytic-Deliberative Decision Making: Evaluating a Large-Group Online Field Experiment, Annals of Association of American Geographers, 101(3):561-586.

Nyerges, T., H. Couclelis, R. McMaster (eds.), (2011) Handbook of GIS \& Society, SAGE Publications, London.

Nyerges, T. and P. Jankowski, (2010), Regional and Urban GIS: A Decision Support Approach. Guilford Press, New York.

Nyerges T., K. Ramsey, and M. Wilson. (2006) Design considerations for an Internet portal to support public participation in transportation improvement decision making. In Collaborative geographic information systems, ed. S. Balram and S. Dragicevic, 208-30. Hershey, PA: Idea Publishing. 
Nyerges, T., M. Roderick, and M. Avraam (2013) CyberGIS Designs of Structured Participation for Collaborative Problem Solving, International Journal for Geographical Information Science, special issue on CyberGIS, 27(11):2146-2159.

Nyerges, T., M. Roderick, S. Prager, D. Bennett, and N. Lam (2014) Foundations of sustainability information representation theory: spatial-temporal dynamics of sustainable systems, International Journal for Geographical Information Science, 28(5):1165-1185. Special issue of Space-Time Research in Geographic Information Science, available as open access at http://www.tandfonline.com/doi/abs/10.1080/13658816.2013.853304\#.Un0G5CcVGSo.

Read, C., (1898) Logic, deductive and inductive, fourth edition, London, Tredition Classics, [1]

Rittel, H. W. and Webber, M. M. (1973) Dilemmas in a general theory of planning. Policy Sciences, 4(2):155-169.

Roderick, M., Nyerges, T. and Avraam, M. (2015) CyberGIS Implementation Considerations for Structured Participation Methods in Collaborative Problem Solving, in S. Wang and M. Goodchild (eds.) CyberGIS: Fostering a New Wave of Geospatial Discovery and Innovation, Springer, New York. In press.

Seattle Times (2015) Open up Seattle's single-family zoning to those who aren't rich, July 19 , 2015. http://www.seattletimes.com/opinion/open-up-seattles-single-family-zoning-to-those-whoarent-rich/

Simon, H. (1977) The new science of management decisions, 3rd ed. Englewood Cliffs, NJ: Prentice-Hall. 
Steinitz, C. (1990) A Framework for Theory Applicable to the Education of Landscape Architects (and other Environmental Design Professionals), Landscape Journal, Fall 1990, pp. 136 - 143.

Steinitz, C. (2012) A Framework for Geodesign, Redlands California, Esri Press.

Steinitz, C. (2013) Beginnings of Geodesign: A Personal Historical Perspective, ArcNews, Summer 2013.

Steinitz, C. (2014a) Beginnings of GIS: A Personal Historical Perspective, Planning Perspectives, January 2014, pp $239-254$.

Steinitz, C. (2014b) Which Way of Designing?, in Lee, D., Dias, E., Scholten H., (Eds.), Geodesign by Integrating Design and Geospatial Sciences, Springer, pp 11 - 43.

Steinitz, C. and Rogers, P., (1970) A Systems Analysis Model of Urbanization and Change: An Experiment in Inter-disciplinary Education. H.G.S.D.,1969; MIT Press.

Sugumaran, R and Degroote, J. (2010) Spatial Decision Support Systems: Principles and Practices. CRC Press, Boca Raton, FL.

Tsolakis, N. and Anthopoulos, L. (2015) Eco-cities: An integrated system dynamics framework and a concise research taxonomy, Sustainable Cities and Society, 17 (2015) 1-14.

UW Geodesign Workshop 2015: Geodesign Dynamics within Complex Sustainable Systems https://www.youtube.com/playlist?list=PL0G3WcDxov2eiltDu1ODmZGZizYP88IV5 
Voss, A., Voss, H., Gatalsky, P., and Oppor, L. (2003) Prototype and further requirements of a real participatory GIS. In Proceedings of the $6^{\text {th }}$ AGILE Conference on Geographic Information Science (Presses Polytechniques et Universitaires Romandes, Lausanne) pp. 613-622.

Vreeker, R., M. Deakin, S. Curwell (eds.) (2009) Sustainable Urban Development, Vol. 3, The Toolkit for Assessment, Routledge, London.

Wang, S., L. Anselin, B. Bhaduri, M. Goodchild, Y. Liu, T. Nyerges, N. Wilkins-Diehr (2013) CyberGIS Software: A Synthetic Review and Integration Roadmap, International Journal for Geographical Information Science, special issue on CyberGIS, 27(11):2122-2145. 


\section{Figure captions}

Figure 1: Steinitz geodesign framework (Steinitz 1990, 2012)

Figure 2: The GeodesignHub.com software in open collaboration mode

Figure 3. The study area focuses on the Lower Green River and Middle Green River subwatersheds.

Figure 4: Cross-systems impacts template.

Figure 5. The six decision model teams with respective system priorities.

Figure 6: Agreement among all design teams on a single final plan, and its impacts for $a+40-$ year horizon. 
Fig. 1

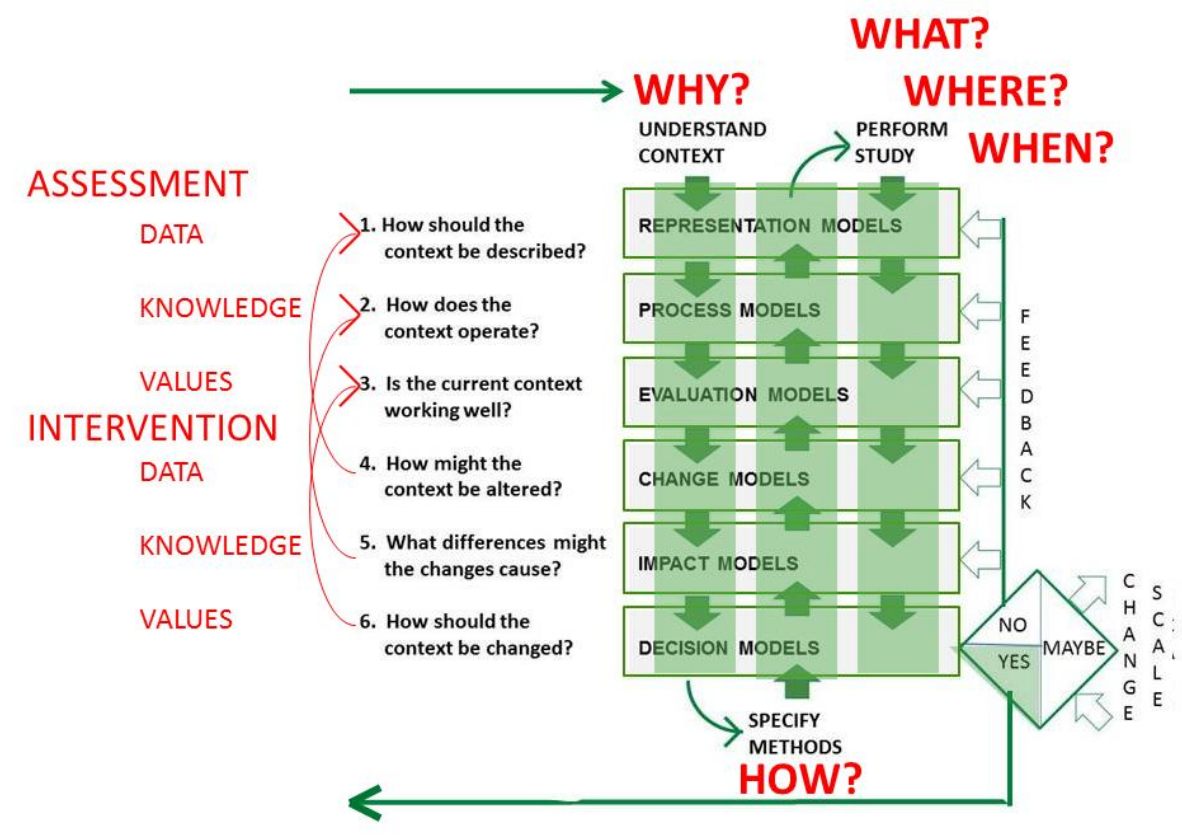


Fig. 2

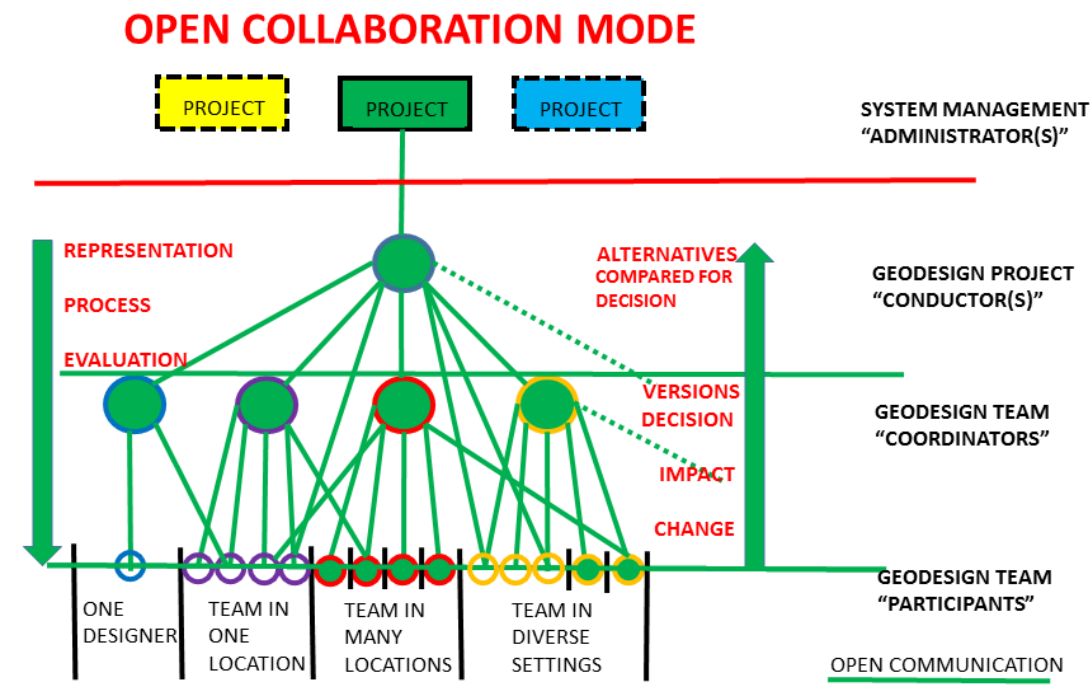


Fig. 3

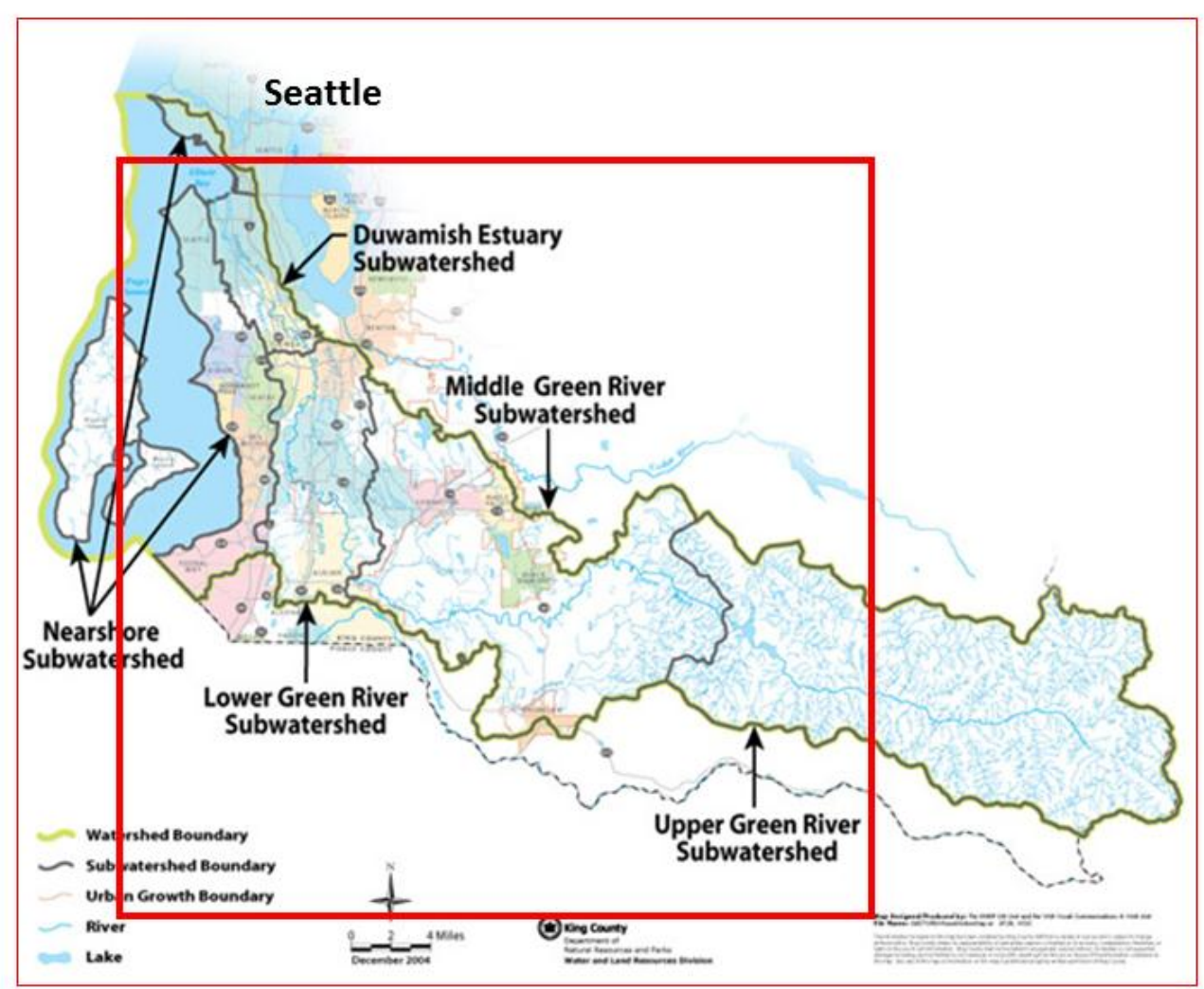


Fig. 4

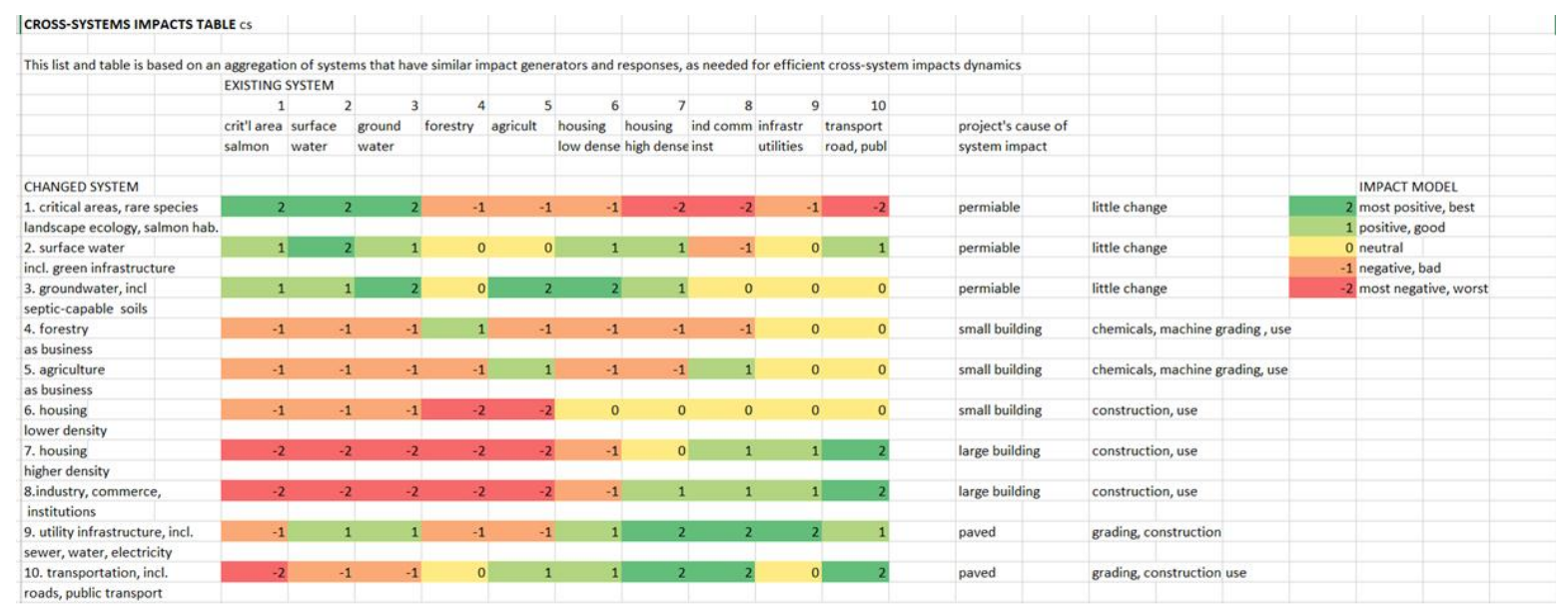


Fig. 5

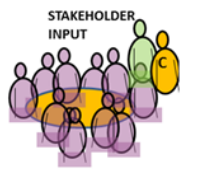

DEVELOPMENTPRIORITIES

Team 1 a) relaxed growth management statutes/policies

Team 2 b) maintaining the current growth management statutes/policies

Team 3 c) enhancing the growth management statutes/policies

\section{CONSERVATION PRIORITIES}

Team 4 a) relaxed growth management statutes/policies

Team 5 b) maintaining the current growth management statutes/policies

Team 6 c) enhancing the growth management statutes/policies
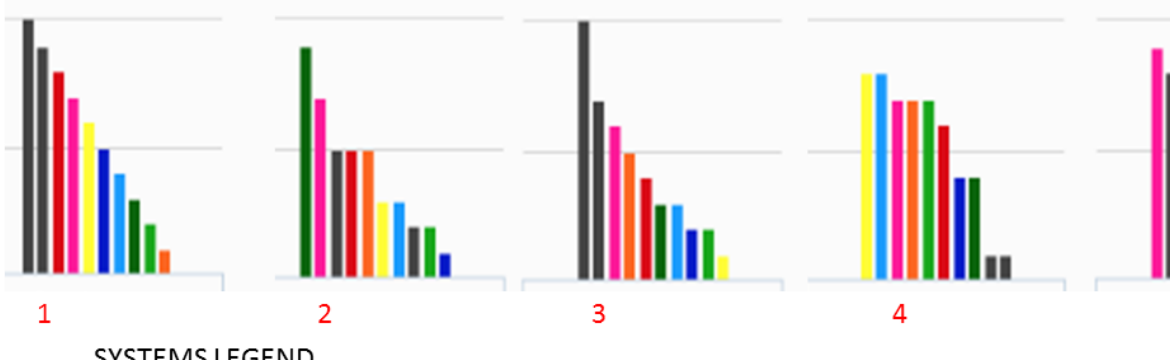

SYSTEMS LEGEND

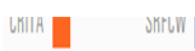

uKnum

เUH

nUN

LUnחNy

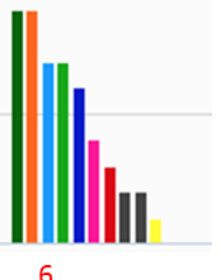

6

IKANIS 
Fig. 6

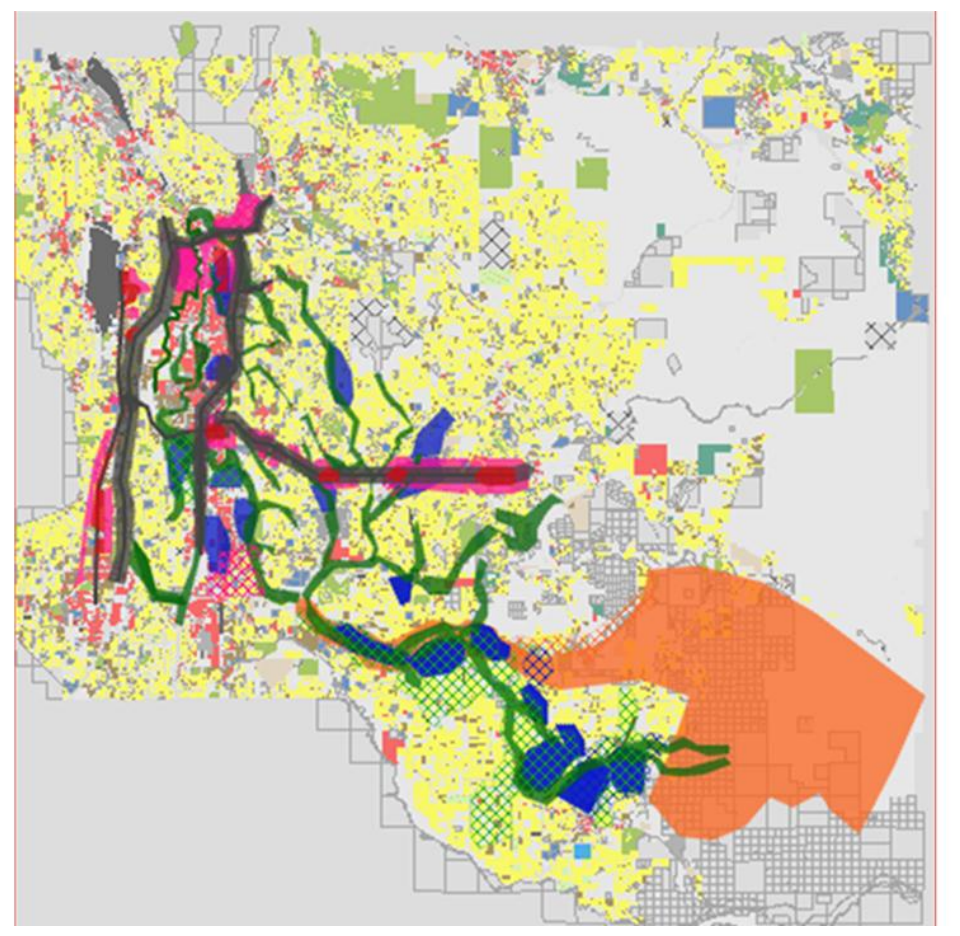

LAND USE +40 YEARS

THE NEGOTIATED DESIGN

Critical resources

Surface water

Groundwater

Forestry

Agriculture

Low density housing

High density housing

Commerce/industry

Infrastructure

Transportation

ए


Tables

Table 1 Ten Systems Considered in the Geodesign Study

\begin{tabular}{|c|c|c|}
\hline WA GMA Elements & $\begin{array}{l}\text { King County } 2013 \text { Plan } \\
\text { Update Chapters }\end{array}$ & Ten Systems of a Watershed \\
\hline Land Use & Chapter 1 Regional Planning & Systems $1-10$ relate to land \\
\hline Housing & Chapter 2 Urban Communities & $\begin{array}{l}6 \text { Low Density Housing } \\
7 \text { High Density Housing }\end{array}$ \\
\hline \multirow[t]{3}{*}{$\begin{array}{l}\text { Rural and Resource } \\
\text { Lands }\end{array}$} & $\begin{array}{l}\text { Chapter } 3 \text { Rural and Natural } \\
\text { Resource Lands }\end{array}$ & $\begin{array}{l}4 \text { Forestry } \\
5 \text { Agriculture Production }\end{array}$ \\
\hline & Chapter 4 Environment & $\begin{array}{l}2 \text { Surface Water } \\
3 \text { Groundwater } \\
4 \text { Forestry }\end{array}$ \\
\hline & $\begin{array}{l}\text { Chapter } 5 \text { Shoreline Master } \\
\text { Program }\end{array}$ & \\
\hline Park and Recreation & $\begin{array}{l}\text { Chapter } 6 \text { Parks, Open Space } \\
\text { and Cultural Resources }\end{array}$ & 1 Critical Areas \\
\hline Transportation & Chapter 7 Transportation & 10 Transportation \\
\hline Capital Facilities & $\begin{array}{l}\text { Chapter } 8 \text { Services, Facilities, } \\
\text { and Utilities }\end{array}$ & 9 Utilities \\
\hline Utilities & $\begin{array}{l}\text { Chapter } 8 \text { Services, Facilities, } \\
\text { and Utilities }\end{array}$ & 9 Utilities \\
\hline Economic & $\begin{array}{l}\text { Chapter } 9 \text { Economic } \\
\text { Development }\end{array}$ & 8 Commercial / Industrial \\
\hline
\end{tabular}


Table 2. Twenty and Forty-year Targets for Ten Subsystems Motivated by Population Growth

\begin{tabular}{|c|c|}
\hline Systems likely to be vulnerable to change & Target Acreage \\
\hline $\begin{array}{l}\text { 1. Critical Areas: Critical areas are defined by King County's Critical Areas } \\
\text { Ordinance (CAO); non-critical areas are differentiated by land cover. }\end{array}$ & $\begin{array}{l}20 \text {-year }=21,000 \\
40 \text {-year }=45,000\end{array}$ \\
\hline $\begin{array}{l}\text { 2. Surface Water: Contamination from land use/cover, considering total } \\
\text { nitrogen contamination from land cover. Threshold recommended standard for } \\
\text { total nitrogen is } 0.53 \text { milligrams/liter set by US EPA. }\end{array}$ & $\begin{array}{l}20-\text { year }=13000 \\
40-\text { year }=30000\end{array}$ \\
\hline $\begin{array}{l}\text { 3. Groundwater: Vulnerability of high value groundwater assets to } \\
\text { contamination in relation to well locations, and sole source aquifers. Follows } \\
\text { roughly King County's Critical Aquifer Recharge Area classifications. }\end{array}$ & $\begin{array}{l}20 \text {-year }=18,000 \\
40-\text { year }=40,000\end{array}$ \\
\hline $\begin{array}{l}\text { 4. Forestry: Forested land cover to be protected. Note: water, perennial snow } \\
\text { and ice, barren land (rock), and wetlands were excluded. }\end{array}$ & $\begin{array}{l}20 \text {-year }=12,000 \\
40 \text {-year }=26,000\end{array}$ \\
\hline 5. Agriculture: Preserve actively used farmland. & $\begin{array}{l}20 \text {-year }=3,500 \\
40 \text {-year }=7,700\end{array}$ \\
\hline \multicolumn{2}{|l|}{ Systems to be developed based on attractiveness for change } \\
\hline $\begin{array}{l}\text { 6. Low density housing: Infill development potential for single-family residential } \\
\text { parcels. }\end{array}$ & $\begin{array}{l}20 \text {-year }=22,000 \\
40-\text { year }=55,000\end{array}$ \\
\hline $\begin{array}{l}\text { 7. High density housing: Infill development potential for multi-family residential } \\
\text { parcels. }\end{array}$ & $\begin{array}{l}20 \text {-year }=3,500 \\
40 \text {-year }=8,500\end{array}$ \\
\hline $\begin{array}{l}\text { 8. Commercial and Industrial: Infill development potential for commercial and } \\
\text { industrial parcels. Note: none of the vacant parcels carry an 'institutional' } \\
\text { designation, so not included in system evaluation. }\end{array}$ & $\begin{array}{l}20 \text {-year }=4,500 \\
40 \text {-year }=11,000\end{array}$ \\
\hline $\begin{array}{l}\text { 9. Utility - Sewer and water: Parcels with no access to public water/sewer } \\
\text { system. }\end{array}$ & $\begin{array}{l}20 \text {-year }=5,500 \\
40 \text {-year }=14,000\end{array}$ \\
\hline $\begin{array}{l}\text { 10. Transportation: Service areas currently without access to public } \\
\text { transportation, including bus, light rail, and commuter rail. Levels below "Most } \\
\text { Attractive" represent access to roads in general. }\end{array}$ & $\begin{array}{l}20 \text {-year }=45,000 \\
40 \text {-year }=110,000\end{array}$ \\
\hline
\end{tabular}

